\title{
A Survey on the health advantages and pharmaceutical employments of south indian musa acuminate (a review)
}

\begin{abstract}
Banana is the basic name for herbaceous plants of the variety Musa and for the natural product they deliver. It is one of the most seasoned developed plants. All parts of the banana plant have therapeutic applications: the blooms in bronchitis and looseness of the bowels and on ulcers; cooked blossoms are given to diabetics; the astringent plant sap in instances of madness, epilepsy, uncleanliness, fevers, hemorrhages, intense diarrhea and the runs, and it is connected on hemorrhoids, creepy crawly and different stings and nibbles; youthful leaves are set as poultices on consumes and other skin torments; the astringent fiery debris of the unripe peel and of the leaves are taken in diarrhea and the runs and utilized for treating harmful ulcers; the roots are directed in stomach related clutters, loose bowels and different afflictions; banana seed adhesive is given in instances of the runs in India. Antifungal and anti-toxin standards are found in the peel and mash of completely ready bananas. The anti-infection acts against Mycobacteria.
\end{abstract}

Volume 7 Issue 4 - 2018

Imtiyaz Rasool Parrey

Govt. Degree College for Womens Anantnag J \& K, India

Correspondence: Govt. Degree College for Womens Anantnag J \& K, India

Received: May 28, 2017| Published: August 09, 2018

\section{Introduction}

Products of the soil are a critical part of a sound eating regimen. A few organic products like bananas offer extraordinary health advantages. This is halfway on the grounds that bananas help in the body's maintenance of calcium, nitrogen, and phosphorus, all of which work to fabricate sound and recovered tissues. In the accompanying passages, we will talk about a portion of these advantages. Bananas can be utilized to battle intestinal clutters like ulcers. Bananas are one of only a handful couple of organic products that ulcer patients can securely expend. Bananas kill the corrosiveness of gastric juices, along these lines decreasing ulcer aggravation by covering the coating of the stomach. Not exclusively would bananas be able to alleviate difficult ulcer frameworks, and other intestinal issue, they can likewise advance recuperating. The organic product is additionally utilized as treatment for consumes and wounds. For prompt help with discomfort, beat a ready banana into a glue and spread it over a copy or wound. For best outcomes, cover the region with a fabric wrap. Indeed, even banana leaves can be utilized as a cool pack for consumes or wounds. Other health advantages of bananas incorporate helping in clogging and looseness of the bowels alleviation, treatment of joint inflammation, and treatment of paleness.

\section{Nutritious value of banana}

Bananas are an astounding wellspring of potassium. Potassium can be found in an assortment of natural products, vegetables, and even meats; in any case, a solitary banana gives you $23 \%$ of the potassium that you require every day. Potassium benefits the muscles as it keeps up their appropriate working and averts muscle fits. Furthermore, late investigations are demonstrating that potassium can diminish circulatory strain in people who are potassium insufficient. Potassium likewise decreases the danger of stroke. Bananas are likewise an incredible wellspring of vitamins, including: ${ }^{1}$ Vitamin A-helps in sound teeth, bones, delicate tissue, and more. ${ }^{2}$ B6-helps the body's resistant framework, advances mind wellbeing, heart wellbeing, and more. ${ }^{3} \mathrm{C}$
- Helps in recuperating, development of tissue, tendons, and more. ${ }^{4}$ D-Causes the body to ingest calcium as you can see by the vitamins introduce, bananas help in keeping the body solid in various routes, however there is a noteworthy advantage to the bones and muscles in the human body. Since bananas contain $41 \%$ of what you require every day in vitamin B6, you will find that eating bananas expands your concentration and mental sharpness. Moreover, bananas help in imperativeness, which implies that you will have more vitality both rationally and physically. Indeed, a few investigations demonstrate that bananas can help enhance your disposition whether you're feeling down or are experiencing PMS. Bananas are additionally a fantastic sustenance for individuals who need to get more fit. Despite the fact that they are somewhat high in calories (200 for every banana) and carbs $(51 \mathrm{gm})$, they are an incredible wellspring of vitality. A banana eaten before an exercise can furnish you with the essential vitality to finish a more drawn out exercise. Bananas give you numerous medical advantages, however notwithstanding the greater part of that, a great many people appreciate eating bananas also. The can be eaten alone or joined with an organic product plate of mixed greens, added to jello, or made into a smoothie or a milkshake. They are a standout amongst the most reasonable natural products in the commercial center and can be discovered year round almost wherever on the planet!

\section{Therapeutic properties of banana beneficial impacts}

a. The organic product has a mellow diuretic property.

b. It is utilized as a cure of blockage in youngsters.

c. It is accepted to be useful in curing looseness of the bowels and diarrhea.

d. The natural product is utilized to recuperate the digestive system sores.

e. It shapes the piece of eating methodologies of kids experiencing 
lack of healthy sustenance.

f. The center of the stem is accepted to be helpful in stomach miracle and diabetes.

g. The concentrate of center of the stem is thought to be valuable in dissolving the stones in the kidney and urinary bladder and diminishing the weight. The inflorescence blended with coconut oil and flavors is utilized for flushing the urinary squares.

h. The natural product is accepted to lessen the worm issues in the children adverse impacts.

i. High sugar nearness joined with tryptophan content in this organic product is dreaded to influence client's condition of mindfulness affecting cerebrum action and bringing tiredness.

j. Migraine cerebral pains might be disturbed by utilization of bananas and liquor. Subsequently, utilization of bananas isn't prudent with liquor.

k. Consumption of bananas may have unfavorably susceptible responses in few individuals. Nutritious properties:

a) Hundred grams of ready Banana gives approx. 116KCal vitality that makes it a supplementary staple sustenance.

b) Banana has generally less proteins contrasted with grains, nonappearance of other protein rich sustenances in the eating regimen can cause protein lack in individuals depending for the most part on Banana as staple nourishment.

c) Cooked or ready Banana are effortlessly processed.

d) Banana is a reasonable wellspring of Vitamin B and Calcium.

e) Banana contains around $20 \%$ sugar.

\section{Restorative qualities}

Bananas are a profoundly nutritious natural product, however do they have any therapeutic properties past their nutritive esteem. ${ }^{5}$ While it might come as an amazement to those of us acclimated with utilizing bananas for heating and banana parts and little else, Perdue University strikingly expresses that all aspects of the banana plant has restorative properties. Among the properties referred to:

Flowers: Used to treat looseness of the bowels, ulcers, and bronchitis. Cooked, blossoms are viewed as a decent nourishment for diabetics.

Sap: Chemically, banana sap has astringent characteristics. In customary pharmaceutical, the sap is utilized to treat a wide assortment of diseases, including infection, agitation, fever, stomach related scatters, drain, epilepsy, hemorrhoids, and bug chomps.

\section{Roots and seeds: Treat stomach related scatters}

Peel and pulp: Scientifically appeared to have both antifungal and anti-infection segments. These structures have additionally been recognized as containing the neurotransmitters norepinephrine, serotonin and dopamine.

\section{Restorative importance}

Decreased danger of hypertension Bananas are outstanding amongst other wellsprings of potassium, a basic mineral for keeping up ordinary circulatory strain and heart work. $A^{6,7}$ medium-sized banana gives $350 \mathrm{mg}$ of potassium. The viability of potassium-rich sustenance's in bringing down pulse has been shown by various examinations. The US Food and Drug Administration have enabled the banana business to make official cases for the organic product's capacity to decrease the danger of circulatory strain and stroke. As indicated by the FDA, "Weight control plans containing nourishments that are great wellsprings of potassium and low in sodium may lessen the danger of hypertension and stroke. Plus potassium enables your body to keep up typical liquid and electrolyte adjusts in the phones. Researchers report that characteristic mixes in bananas act in a way like antihypertensive medications. The group contemplated six famous banana assortments and found that all had ACE inhibiting properties however the aged bananas had a more grounded activity than unripe ones. Scientists have revealed that pulse fell by $10 \%$ in individuals who ate two bananas every day for seven days.

\section{Stroke}

Researchers recommend that individuals with a low measure of potassium in their eating regimen may have an expanded danger of stroke. An investigation of 5,600 individuals matured more than 65 found that those with the most reduced admission of the potassium were half more inclined to endure a stroke. High-potassium nourishments, similar to bananas, may bring down the danger of stroke, yet specialists say that more examinations are expected to affirm in the case of expanding potassium in the eating regimen can anticipate strokes. ${ }^{8}$

\section{Reestablish typical gut activity}

Since the banana is rich in nondigestible strands (counting cellulose, hemicellulose, and alphaglucans) it can help reestablish ordinary inside movement and help with both clogging and looseness of the bowels. Bananas standardize the colon's capacity to assimilate a lot of water for consistent solid discharges. Their helpfulness is because of their lavishness in gelatin, which is water-retentive and this gives them a mass creating capacity. Bananas are an uncommonly rich wellspring of fructo oligosaccharide, a compound called a prebiotic in light of the fact that it feeds probiotic (cordial) microscopic organisms in the colon. These gainful microscopic organisms create vitamins and stomach related proteins that enhance our capacity to retain supplements, in addition to exacerbates that secure us against antagonistic microorganisms. At the point when fructooligosaccharides are matured by these inviting microbes, do quantities of probiotic microorganisms increment, as well as so does the body's capacity to retain calcium. Hence, ingesting anti-microbials hurt these advantageous microorganisms. Research distributed in Digestive Diseases and Sciences underscores exactly how much bananas can enhance supplement ingestion. In this investigation, 57 babies ( 5 a year) with tenacious looseness of the bowels of no less than 14 days span were given seven days' treatment with a rice-based eating regimen containing either green banana, apple gelatin or the rice abstain from food alone. Treatment with both green banana and apple gelatin brought about a half diminishment in stool weights, showing that the infants were retaining fundamentally more supplements., ${ }^{9,10}$

\section{Insurance from ulcers and heartburn}

cure Bananas have for quite some time been perceived for their acid neutralizer impacts that ensure against stomach ulcers and ulcer harm. A flavonoid in the banana, leucocyanidin, has been found to altogether build the thickness of the mucous film layer of the stomach. Since bananas help to kill acridity, they are additionally an incredible 
method to dispose of indigestion. ${ }^{11}$ In a creature examine a basic blend of banana and drain essentially smothered corrosive discharge.

\section{Security against neurodegenerative illnesses (Alzheimer's infection)}

Scientists at Cornell University researched the impacts of apple, banana, and orange concentrates on neuron cells and found that the phenolic phytochemicals of the natural products averted neurotoxicity on the cells. Among the three natural products, apples contained the most elevated substance of defensive cancer prevention agents, trailed by bananas then oranges. ${ }^{12-14}$ These outcomes propose that crisp apples, banana, and orange in our day by day consume less calories alongside different organic products may secure neuron cells against oxidative pressure prompted neurotoxicity and may assume an imperative part in decreasing the danger of neurodegenerative issue, for example, Alzheimer's ailment.

\section{Conclusion}

The banana is of awesome wholesome esteem. It has an uncommon mix of vitality esteem, tissue-building components, protein, vitamins and minerals. It is a decent wellspring of calories since it is rich in solids and low in water content when contrasted with some other crisp natural product. Bananas are a decent wellspring of Vitamin C which revamps the safe framework. Bananas are additionally generally simple to process when contrasted with different sustenances thus they are precious to those with bargained safe frameworks. Vitamin $\mathrm{C}$ additionally builds the ingestion of iron and expands the arrangement of blood, these two medical advantages of bananas make it preferably suited for those with frailty or blood related issues. Bananas can likewise be incorporated into an eating regimen for hypertension as they contain potassium which lessens and control hypertension. Moreover, bananas don't contain even follow measures of fat, cholesterol, or sodium which makes it a solid nourishment alternative notwithstanding for prohibitive eating routine designs. There are a few sorts of bananas which are arranged by their taste and the shade of their skin. Red bananas have a red peel and the substance of the organic product is light pink in shading. Red bananas are ideal in the event that they are permitted to mature completely at room temperature. They can be utilized to include a dash of shading and sweetness to a blended organic product platter. Apple bananas are littler than the standard assortments of bananas and are yellow in shading. They have a tendency to age substantially speedier thus it is critical to beware of them consistently to guarantee that they don't get spoilt. The child banana is one of the littlest assortments of bananas and they are yellow in shading. They are sweet and are ideal for babies and little children. It is best to mix these bananas into a thick puree before sustaining it to newborn children. Heating bananas are extensive and are regularly utilized as a part of prepared dishes as a one of a kind and outlandish substitute for potatoes. Ready banana medical advantages are extremely shifted thus the medical advantages of ready bananas ought to be considered when settling on an eating regimen design.

\section{Acknowledgements}

None.

\section{Conflict of interest}

The author declares that there is no conflict of interest.

\section{References}

1. Jahan M. Concentration influence on antimicrobial activity of banana blossom extract- incorporated chitosan-polyethylene glycol (CS- PEG) blended film. Journal of Chemical and Pharmaceutical Research. 2010.

2. Bagavan A. In vitro antimalarial activity of medicinal plant extracts against Plasmodium falciparum. Parasitol Res. 2011;108(1):15-22.

3. Pari L. Antihyperglycaemic activity of Musa sapientum flowers: effect on lipid peroxidation in alloxan diabetic rats. Phytother Res. 2000;14(2):136138 .

4. Loganayaki N. Antioxidant capacity and phenolic content of different solvent extracts from banana (Musa paradisiaca) and mustai (Rivea hypocrateriformis). Food and Science Biotechnology. 2010;19(5):12511258 .

5. Bananas, The world's healthiest foods. 2005.

6. Emery EA. Banana flakes control diarrhea in enterally fed patients. Nutr Clin Pract. 1997;12(2):72-75.

7. Lohsoonthorn P, Danvivat D Colorectal cancer risk factors: a case-control study in Bangkok. Asia Pac J Public Health. 1995;8(2):118-122.

8. Sun J. Antioxidant and antiproliferative activities of common fruits. $J$ Agric Food Chem. 2002; 50(25):7449-7454.

9. Penagos H. Pesticide patch test series for the assessment of allergic contact dermatitis among banana plantation workers in panama. Dermatitis. 2004; 15(3):137-145.

10. Swanson MD. A lectin isolated from bananas is a potent inhibitor of HIV replication. J Biol Chem. 2010;285(12):8646-8655.

11. Horigome T. Hypocholesterolemic effect of banana (Musa sapientum L. var. Cavendishii) pulp in the rat fed on a cholesterol-containing diet. Br J Nutr. 1992;68(1):231-244.

12. Blades BL. Bananas and plantains as a source of provitamin A. Asia Pac J Clin Nutr. 2003;12(Suppl):S36.

13. Bhaskar JJ. Banana (Musa sp. var elakki bale) Flower and Pseudostem: Dietary Fiber and Associated Antioxidant Capacity. J Agric Food Chem. 2011;60(1):427-432.

14. Hettiaratchi UP. Chemical compositions and glycemic responses to banana varieties. Int J Food Sci Nutr. 2011;62(4):307-309. 